This study won the ML Roberts prize awarded for the best 4th year undergraduate research project at the Department of Physiotherapy, Auckland University of Technology in 2014. NZJP publishes the resulting paper without external peer review.

\title{
Do hydrotherapy exercise programmes improve exercise tolerance and quality of life in patients with chronic heart failure? A systematic review
}

Bianca Graetz BHSC

Rotational Physiotherapist, Middlemore Hospital, Auckland

Marcus Sullivan BHSC

Physiotherapist, Physiotherapy Department, North Shore Hospital, Auckland

Trina Robertson NZRP, BSC (Hons) Physiotherapy

Senior Physiotherapist, North Shore Hospital, Auckland

Julie Reeve PhD, MSc, Grad Dip Phys

Senior Lecturer, Division of Rehabilitation and Occupation Studies, Auckland University of Technology, Auckland.

\section{ABSTRACT}

The purpose of this study was to evaluate whether hydrotherapy programmes improve exercise tolerance and quality of life in patients with chronic heart failure. Data sources utilised were EBSCO, Scopus, Medline, PubMed, OVID, Proquest, PEDro and Cochrane Systematic Reviews databases. A systematic review of randomised controlled trials or quasi randomised controlled trials investigated hydrotherapy compared with a suitable control. Methodological quality was assessed using a modified version of the Downs and Black critical appraisal tool. Findings demonstrated that hydrotherapy was well tolerated with few adverse events reported. Two studies demonstrated hydrotherapy intervention groups significantly improved 6MWT from baseline ( $p \leq 0.05)$, while two studies found significantly greater improvements when compared to non-exercising $(p=0.01)$ and land based exercising $(p=0.001)$ controls. Four studies found significant gains $(p \leq 0.05)$ in $\mathrm{VO}_{2}$ peak from baseline following hydrotherapy interventions. Two studies reported significant $(p=0.01$ ) intragroup improvements in total score of the Minnesota Living with Heart Failure Questionnaire in hydrotherapy intervention groups when compared with baseline and a non-exercising control respectively. In conclusion, hydrotherapy exercise programmes were well tolerated and appear to improve exercise capacity and quality of life in people with chronic heart failure but firm conclusions could not be drawn due to the poor to moderate quality of the evidence.

Graetz B, Sullivan M, Robertson T, Reeve J (2015) Do hydrotherapy exercise programmes improve exercise tolerance and quality of life in patients with chronic heart failure? A systematic review New Zealand Journal of Physiotherapy 43(2): 64-71. DOI: 10.15619/NZJP/43.2.07

\section{INTRODUCTION}

Chronic heart failure (CHF) is an inability of the heart to deliver adequate oxygen to metabolising tissues (NZ Heart Foundation 2009). This occurs as a result of changes in cardiac structure and/ or function, and is most commonly caused by coronary artery disease (including myocardial infarction), valvular disease and cardiac myopathy (Carvalho and Guimaraes 2010). This has implications for patient function, as any increase in oxygen demand that occurs with an increase in activity may not be met. As a result, people with CHF often experience an increase in symptoms of breathlessness and fatigue and a resultant reduction in exercise tolerance and quality of life (Somaratne et al 2009). While there is no single diagnostic test for CHF, the New York Heart Association (NYHA) scale classifies the progression of CHF based on a patient's symptomatic status and exercise capacity (Yancy et al 2013). The stages range from stage 1 (No limitation of physical activity) through to stage 4 (Unable to carry out any physical activity without symptoms of HF or symptoms of HF at rest) (American Heart Association 2014). Exercise-based rehabilitation improves symptoms of $\mathrm{CHF}$ by improving peripheral haemodynamic and physiological efficiency, thus reducing cardiovascular demands (Piepoli et al 2010). Cardiac rehabilitation programmes have been shown to reduce disease affected life years and hospital admissions in patients with CHF (Taylor et al 2014). As such, exercise based cardiac rehabilitation programmes have proven benefits on personal and likely economic levels.

Cardiovascular disease has been identified as a health priority in New Zealand, due to its significant burden on the annual healthcare budget (NZ Heart Foundation 2009). In New Zealand, there are more than five thousand patients living with CHF, resulting in 12,000 hospitalisations per year. As a result, CHF accounts for approximately $2 \%$ of total health care expenditure each year (NZ Heart Foundation 2009). Treatment of CHF typically includes a combination of pharmaceutical management and physical rehabilitation (Mant et al 2011). CHF is prevalent in the older population (Go et al 2013), with this demographic exhibiting a high proportion of physical comorbidities (Wong et al 2011). This may present challenges for medical management, and barriers to land-based exercise interventions. As such, alternative modes of exercise, such as hydrotherapy, may be useful in overcoming such barriers to land-based programmes. 
Hydrotherapy has been used since the early Greco-Roman era as a treatment for ailments and illness (Bender et al 2005). In modern times, hydrotherapy has been shown to be useful in improving functional outcomes for patients with chronic neurologic and musculoskeletal conditions, including osteoarthritis (Kamioka et al 2010). However, the literature surrounding hydrotherapy for cardiac conditions is still in its infancy. To the authors' knowledge, at the time of undertaking this review, the evidence for hydrotherapy as an alternative form of exercise for patients with CHF had not been reviewed. Therefore, the aim of this study was to systematically review the literature to determine the effects of hydrotherapy programmes on exercise tolerance and quality of life in patients with CHF.

\section{METHODS}

A systematic review of the literature to ascertain the efficacy of aquatic-based exercise on exercise tolerance and health related quality of life (HRQOL) was undertaken. The Preferred Reporting Items for Systematic Reviews and Meta-Analyses (PRISMA) guideline was utilised in undertaking this systematic review. The PRISMA guideline was developed to improve standards of reporting meta-analyses and systematic reviews (Moher et al 2010). Undertaking a meta analysis of the data was deemed beyond the scope of this project.

\section{Data sources and search strategy}

The electronic databases of EBSCO, Scopus, Medline, PubMed, OVID, Proquest, PEDro and Cochrane Systematic Reviews were searched over a period from March 2014 to April 2014. These databases were chosen based on their inclusion of allied health and medical journals, and those that contain studies relevant to exercise-based rehabilitation. The search terms included "hydrotherapy", "immersion therapy", "aquatic exercise" and for the intervention including "heart failure". A full keyword search strategy has been included in Appendix A.

\section{Inclusion criteria}

Studies were eligible for inclusion if they were randomised controlled trials or quasi-experimental trials comparing a waterbased exercise programme to a suitable control. To be eligible for inclusion, studies must have examined the effect of waterbased activity on exercise tolerance and HRQOL in patients with CHF. Studies were excluded if participants did not perform any movement in water. The participants had to be human, and have a diagnosis of stable CHF, with a NYHF classification of two to three. A full list of inclusion and exclusion criteria has been included in Appendix B.

Two researchers (BG and MS) concurrently applied the inclusion and exclusion criteria to all studies that were retrieved. Both researchers participated in all stages of the screening process, including title, abstract and full text screening. Any studies that clearly did not meet the criteria were eliminated. For any studies that were not clear, the abstract and/or full text was retrieved for analysis. Both researchers agreed on all studies included in this review by consensus, without the need for mediation. Both BG and MS screened all included studies for any further appropriate studies.

\section{Data extraction and quality assessment}

Eligible studies were assessed for methodological quality using a modified version of the Downs and Black checklist (Downs and Black 1998). This checklist consists of 27 questions that can be applied to experimental or observational studies. Each question is allocated a score of 0,1 or 2, with higher scores indicating a higher overall quality of study. The checklist has been shown to be a valid and reliable tool for the assessment of experimental trials. The checklist was applied to all studies included in this review by two assessors (BG and MS) independently. Results of both independent evaluations were compared, and any discrepancies were discussed until a consensus was reached.

\section{RESULTS}

\section{Literature search}

Database searching yielded a total of 1616 potential studies to be included in this review. Duplicates were removed $(n=178)$ and an initial title screening resulted in the exclusion of 1438 titles. Following the abstract and full text screening process, six studies were identified to be included in the final analysis (Caminiti et al 2009, Cider et al 2003, Cider et al 2012, Mourot et al 2010, Munincino et al 2006, Teffaha et al 2011). The process of study selection, elimination and reasons for exclusion is included in Figure 1.

\section{Figure 1: Search Strategy Flow Chart}

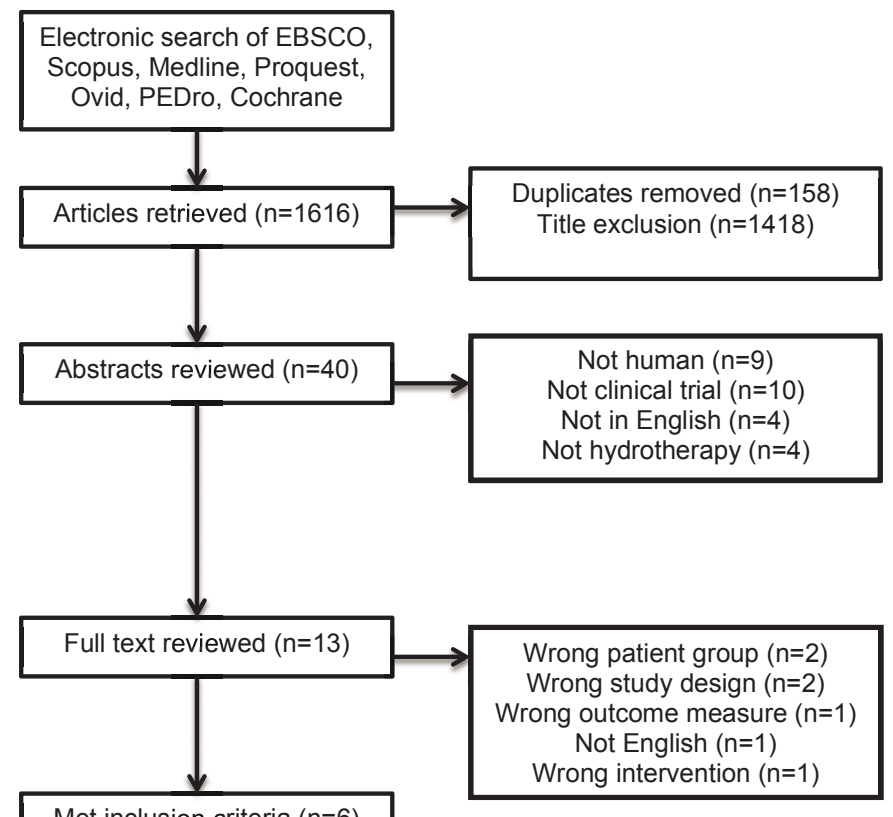

Met inclusion criteria $(n=6)$

\section{Summary of included studies}

Methodological quality assessment

The methodological quality of studies ranged from poor (9/28) to moderate (20/28). All studies failed to blind participants and assessors, and all studies failed to report an adjustment for confounding factors in their data analysis. Total scores for each of the included studies are presented in Table 1.

\section{Study design}

Of the six studies that met the inclusion criteria, four were randomised controlled trials (Caminiti et al 2009, Cider et al 2003, Cider et al 2012, Teffaha et al 2011). Two studies compared hydrotherapy to land based exercise programmes (Caminiti et al 2009, Teffaha et al 2011). Cider et al (2003, 2012) compared hydrotherapy to usual care (no increase in habitual physical activity) and two studies were feasibility studies of repeated measures design, in which the participants served as their own controls (Mourot et al 2010, Municino et al 2006). Details of the programme, participants, intervention and control groups are outlined in Table 2. 


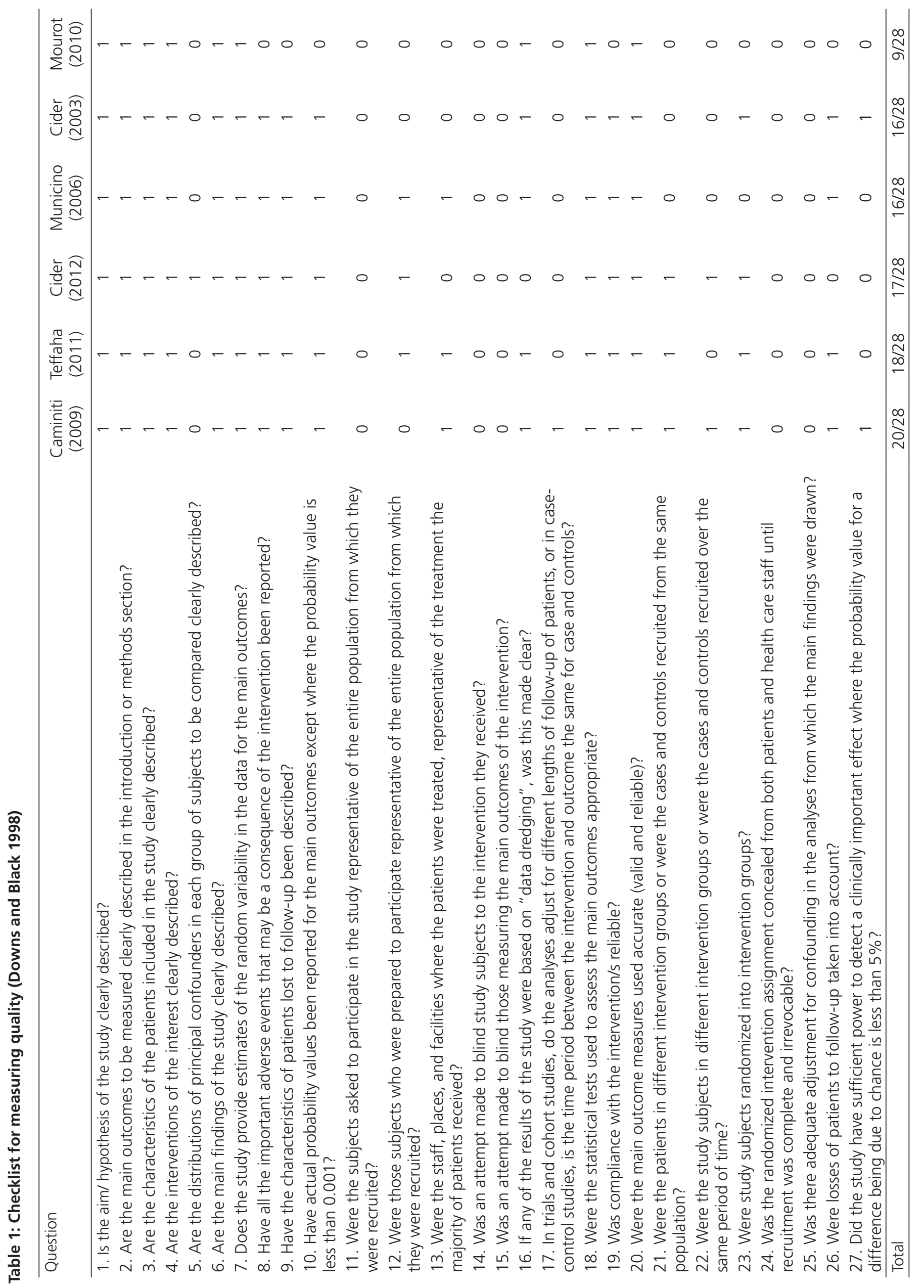


Table 2: Study Summary and Results

\begin{tabular}{|c|c|c|c|c|c|}
\hline \multirow[b]{2}{*}{ Study } & \multicolumn{2}{|l|}{ Participants } & \multicolumn{3}{|l|}{ Intervention } \\
\hline & Experimental & Control & Experimental & Control & Main Findings \\
\hline \multirow{5}{*}{$\begin{array}{l}\text { Caminiti et al } \\
(2009)\end{array}$} & $n=11$ & $n=10$ & 24-week programme: & \multirow{5}{*}{$\begin{array}{l}24 \text { weeks - } \\
\text { Endurance training } \\
\text { only; } 1-\mathrm{hr}, 3 \times \mathrm{per} \\
\text { week for (60-70\% } \\
\left.\mathrm{VO}_{2 \max }\right)\end{array}$} & \multirow{5}{*}{$\begin{array}{l}\text { Combined group } \\
\text { significantly improved } \\
6 \mathrm{MWT} \text { compared to } \\
\text { baseline and land-based } \\
\text { controls }(p<.001)\end{array}$} \\
\hline & \multirow{2}{*}{$\begin{array}{l}\text { M/F: 11/0 } \\
\text { *Age: } 67 \text { (6) }\end{array}$} & M/F: $10 / 0$ & \multirow{3}{*}{$\begin{array}{l}\text { Combined endurance } \\
\text { training and } \\
\text { hydrotherapy; 1-hr, } 3 \text { x } \\
\text { per week }\end{array}$} & & \\
\hline & & *Age: 69 (8) & & & \\
\hline & NYHA $\|=7$ & NYHA $\|=6$ & & & \\
\hline & NYHA III = 4 & $\mathrm{NYHA} \| I I=4$ & No intensity specified & & \\
\hline & $n=15$ & $n=10$ & & & $\begin{array}{l}\text { No significant findings } \\
\text { from baseline or between }\end{array}$ \\
\hline & $\mathrm{M} / \mathrm{F}: 11 / 5$ & M/F: 6/3 & 8-week programme: & & groups for aerobic \\
\hline$(2003)$ & *Age: 70.2 (5.2) & *Age: 75 (6.4) & 45 min, $3 \times$ per week. & increase in habitual & measures. \\
\hline (2) & NYHA $\|=3$ & NYHA $\|=1$ & level (40-70\%HRR) & pny & Significantly improved \\
\hline & NYHA III = 12 & NYHA III = 9 & & & $\begin{array}{l}\text { MLHFQ total score, but } \\
\text { not more than controls }\end{array}$ \\
\hline & $n=10$ & $n=10$ & & & Improved $\mathrm{VO}_{2}$ and \\
\hline Cider & $\mathrm{M} / \mathrm{F}: 8 / 2$ & $\mathrm{M} / \mathrm{F}: 8 / 2$ & 8-week programme: & Live life as usual, no & 6MWT compared to \\
\hline$(2012)$ & ${ }^{\star}$ Age: 65.8 (5.8) & *Age: 69 (8.2) & 45 min, $3 \times$ per week. & increase in habitual & Alocianifirant betwen \\
\hline & NYHA $\|=5$ & NYHA $\|=3$ & level (40-75\%HRR) & ty & group differences in \\
\hline & NYHA III = 5 & NYHA III = 7 & & & HRQOL outcomes \\
\hline & $n=24$ & & 3-week programme & & \\
\hline & M/F: 24/0 & & Water-based gymnastic & & \\
\hline Mourot et al & *Age: 53 (4) & & exercises, 40 min, 3-4 x & Own control - & Significantly improved \\
\hline (2010) & $\begin{array}{l}\text { NYHA: Not } \\
\text { reported }\end{array}$ & Own control & Land-based endurance & $\begin{array}{l}\text { measured pre and } \\
\text { post-intervention }\end{array}$ & $\begin{array}{l}\mathrm{VO}_{2 \text { peak }} \\
(\mathrm{p}<.05)\end{array}$ \\
\hline & $\mathrm{CHF}=12$ & & min, 4-5 x per week @ & & \\
\hline & $C A D=12$ & & $60-70 \%$ HRR) & & \\
\hline & $n=18$ & & 3-week programme: & & \\
\hline & $\mathrm{M} / \mathrm{F}: 7 / 1$ & & $2 \times 30-50 \mathrm{~min}$ & & \\
\hline Municino et al & *Age: 63 (10) & Own control & $\begin{array}{l}\text { hydrotherapy sessions } \\
\text { per day. }\end{array}$ & all participants & in $6 \mathrm{MWT}, \mathrm{VO}_{2 \text { peak }}$ and \\
\hline (2006) & NYHA $\|=9$ & & Educational and psycho- & post-intervention & $(p<.05)$ \\
\hline & NYHA III = 7 & & behavioural support & & \\
\hline & NYHA IV $=2$ & & sessions 5 x per week. & & \\
\hline & $n=24$ & & & 3-week programme: & \\
\hline & M/F: 24/0 & $11=24$ & 5 - & $5 \times$ per week, $35 \mathrm{~min}$ & \\
\hline & *Age: 51.7 (3.6) & $* 1$ & o x per weer & Land-based & $\begin{array}{l}\text { Hydrotherapy CHF group } \\
\text { improved VO from }\end{array}$ \\
\hline (2011) & CHF NYHA $\|=1$ & Age. 53.3 (4.2) & calisthenics & endurance and & baseline, and significantly \\
\hline$(2011)$ & $\begin{array}{l}\text { CHF NYHA III } \\
=11\end{array}$ & CHF NYHA III = 10 & Individualised target & Individualised target & $\begin{array}{l}\text { more than land-based } \\
\text { control }(p<.05)\end{array}$ \\
\hline & $\begin{array}{l}\text { CAD NYHA II } \\
=12\end{array}$ & CAD NYHA $\|=12$ & testing & $\begin{array}{l}\text { intensity based on } \\
\text { initial testing }\end{array}$ & \\
\hline
\end{tabular}

Note: * Age is mean (standard deviation); $\mathrm{M}$, male; $\mathrm{F}$, female; NYHA, New York Heart Association; $\mathrm{VO}_{2 \text { max' }}$ maximal oxygen uptake; HRR, heart rate reserve; CHF, chronic heart failure; CAD, coronary artery disease; 6MWT, Six Minute Walk Test; HRQOL, Health Related Quality of Life; MLHFQ, Minnesota Living with Heart failure questionnaire; $\mathrm{VO}_{2 \text { peak, }}$, peak oxygen uptake. 


\section{Participants}

Across all studies, a total of 174 participants with CHF were investigated, of whom 18 were female. The mean age of all participants was 63.5 years. Patients were included in all studies based on a clinical diagnosis of CHF. All studies apart from Mourot et al (2010) reported NYHF classification, primarily of II-III, however one study (Municino et al 2006) included two participants of NYHA IV. All studies reported left ventricular ejection fraction (LVEF) of $\leq 45 \%$. Participants were excluded if they had unstable CHF, peripheral artery disease, fear of water, any contraindications to exercise testing or disabling diseases that may have interfered with the exercise protocol.

\section{Programme components}

Duration: Programmes ranged from three to 24 weeks. Three of the six studies extended over eight or more weeks (Caminiti et al 2009, Cider et al 2003, Cider et al 2012). Three studies were conducted over three weeks (Mourot et al 2010, Municino et al 2006, Teffaha et al 2011). Exercise sessions ranged from 30 to 50 minutes, with session frequency ranging from twice weekly to two sessions daily five times per week. Details of the programme components have been outlined in Table 2 .

Location/water temperature: Programmes were carried out in hospital rehabilitation pools across Europe - in Sweden (Cider et al 2003, Cider et al 2012), France (Mourot et al 2010, Teffaha et al 2011) or in Italy (Caminiti et al 2009, Municino et al 2006). Water temperature was set between 31-34 degrees Celsius for all studies.

Intensity: Intensity was reported across all studies as a target heart rate reserve (HRR) or as a percentage of $\mathrm{VO}_{2 \text { peak }}$. Target heart rate ranged from 40-70\% HRR in three studies (Cider et al 2003, Cider et al 2012, Mourot et al 2010). Two studies measured intensity using results of oxygen consumption testing or $\mathrm{VO}_{2 \text { peak }}$ (Municino et al 2006 a, Teffaha et al 2011). The target $\mathrm{VO}_{2}$ in these studies ranged from $40-70 \% \mathrm{VO}_{2 \text { peak/max }}$ One study (Caminiti et al 2009) did not identify specific target intensities, instead reporting that a target $\mathrm{VO}_{2}$ was individualised to the patient based on initial testing.

Adverse events: Three patients (intervention group) across two studies were withdrawn from the programme due to: peripheral ulcer $(n=1)$, increase in CHF symptoms $(n=1)$ (Cider et al 2012) and the recurrence of a preexisting cardiac arrhythmia $(n=1)$ (Cider et al 2003). No other adverse events were reported. One study failed to report adverse events (Mourot et al 2010).

Adherence: Across all studies one participant withdrew themselves from the programme due to family problems (Cider et al 2012). One study (Mourot et al 2010) failed to report adherence. One study (Teffaha et al 2011) reported two temporary withdrawals due to bronchopulmonary infection $(n=1)$ and medication mismanagement $(n=1)$. Both patients resumed the programme after a one-week absence, completing the programme without any complications.

Outcomes - measures of exercise tolerance

Six-minute walk test: The six-minute walk test (6MWT) was used to measure functional exercise capacity in four studies (Caminiti et al 2009, Cider et al 2003, Cider et al 2012, Municino et al 2006). Two studies (Caminiti et al 2009, Municino et al 2006) found that hydrotherapy intervention groups significantly improved their 6MWT from baseline $(p \leq 0.05)$, with Caminiti et al (2009) finding significantly greater improvements compared to a land-based exercise group ( $p=0.001$ ). A third study (Cider et al 2012) found significantly improved 6MWT in a hydrotherapy intervention group compared with a usual activity control group $(p=0.01)$, which consisted of land based participants not permitted to increase their usual level of daily physical activity. Two studies (Cider et al 2003, Munincino et al 2006) recorded gains in 6MWT of $29.7 \mathrm{~m}$, and $118 \mathrm{~m}$, respectively, whilst one study (Caminiti et al 2009) recorded improvements of $150 \mathrm{~m}$ when compared to baseline and $37 \mathrm{~m}$ when compared to a land based exercise group. Cider et al (2012) reported significant gains in 6MWT in the hydrotherapy group versus a usual activity control group, however actual distances were not reported. A summary of these findings is provided in Table 2

Oxygen consumption: Five studies investigated exercise tolerance by measuring peak oxygen uptake $\left(\mathrm{VO}_{2 \text { peak }}\right)$ during a cycle ergometry test (Cider et al 2003, Cider et al 2012, Mourot et al 2010, Municino et al 2006, Teffaha et al 2011). Four studies (Cider et al 2012, Mourot et al 2010, Municino et al 2006, Teffaha et al 2011) found significant gains from baseline following hydrotherapy interventions, with one of these intervention groups improving significantly more than usualactivity controls (Cider et al 2012). Improvements in $\mathrm{VO}_{2}$ ranged from 1.0 to $2.1 \mathrm{~mL} \cdot \mathrm{kg}-1 \cdot \mathrm{min}-1$ across the five studies.

Outcomes - measures of health related quality of life Health Related Quality of Life Questionnaires: Health related quality of life (HRQOL) was investigated in three studies using the Minnesota Living with Heart Failure Questionnaire (MLHFQ) (Cider et al 2003, Cider et al 2012, Municino et al 2006) and the SF-36 (Cider et al 2003, 2012). Anxiety and depression were measured by the Hospital Anxiety and Depression Scale in one study (Cider et al 2012). Significant within group improvements were found in two of these studies for the combined total of MLHFQ total score (Cider et al 2003, Municino et al 2006) and physical domain (Cider et al 2003). One study (Cider et al 2012) did not find any significant improvements in total MLHFQ scores compared to baseline or control. This study did find significant results following hydrotherapy intervention compared with a healthy Swedish reference population with significantly lower SF-36 scores across all domains except bodily pain $(p<0.05)$.

\section{DISCUSSION}

Hydrotherapy has been proposed as an alternative to traditional land-based exercise programmes for people with CHF, however the literature surrounding hydrotherapy as an effective intervention for this patient group is still in its infancy. Regular physical activity is advocated in patients with chronic heart failure (CHF), due to proven benefits in patient function (Selig et al 2010). Several high-quality randomised controlled trials have shown that regular exercise leads to improvements in exercise tolerance (Piepoli et al 2010, Taylor et al 2014) and quality of life (Garin et al 2009, Taylor et al 2014), as well as reducing hospital admissions and mortality rates in CHF patients of either reduced or preserved ejection fraction and NYHA class II-III when compared with no exercise controls (Taylor et al 2014). These benefits are thought to arise from peripheral adaptations, such as improved vascularity and metabolic adaptation in skeletal muscle cells, allowing for increased energy production and improved metabolic efficiency (Piepoli et al 2010). In the present systematic review, we identified six studies comparing hydrotherapy versus no exercise or land-based exercise training in people with stable CHF, with the aim of determining the effects of hydrotherapy on exercise tolerance and quality of life in this patient group.

It has been proposed that the resistance of hydrostatic pressure when moving through water may deliver a greater training stimulus than land-based exercise (Becker 2009). Therefore, it would seem reasonable to hypothesise that water-based exercise may be of significant benefit to patients with $\mathrm{CHF}$ due to the 
added resistance of hydrostatic pressure in conjunction with the proposed haemodynamic benefits of warm-water immersion. Conversely, it has also been suggested that the immersion of patients with CHF in water may be detrimental to function, as the increase in hydrostatic pressure exerted on the body may increase the load on an already deficient cardiovascular system (Working Group on Cardiac, Rehabilitation, Exercise, Physiology, \& Working Group on Heart Failure of the European Society of Cardiology). However, recent evidence has shown that static warm water immersion leads to physiological responses in patients with CHF that include acute peripheral vasodilation, a reduction in peripheral resistance, and an increase in venous return (Gabrielsen et al 2000). Svealv et al (2009) investigated the effect of an 8-week hydrotherapy programme on static physiological responses to warm water immersion in patients with chronic heart failure. These authors found that static warm water immersion results in a significant acute reduction in peripheral resistance and heart rate with significant improvements in venous return and stroke volume. However, these effects were neither significantly improved upon, nor maintained following 8 weeks of hydrotherapy exercise.

The main aim of cardiac rehabilitation programmes is to improve function, exercise tolerance and quality of life (NZ Heart Foundation 2009). Exercise tolerance is commonly measured using the 6MWT as it is a valid, reliable, functional and clinically accessible outcome measure in this population (Shoemaker et al 2012). Exercise tolerance was investigated using the 6MWT in four studies included in this systematic review (Caminiti et al 2009, Cider 2003, Cider et al 2012, Municino et al 2006). Half of the studies included in this review achieved significant 6MWT improvements from baseline scores following a hydrotherapy exercise programme (Caminiti et al 2009, Cider et al 2012, Municino et al 2006). The minimal clinically important difference (MCID) for the 6MWT for patients with CHF has been found to be 40-45m (Shoemaker et al 2012) and the improvements recorded in the studies of both Munincino et al (2006) and Caminiti et al (2009) exceeded this. It should be noted that both these studies had a greater number of exercise sessions ( 30 sessions and 72 sessions, respectively), when compared with Cider et al (2003, 2012), which each consisted of 24 sessions.

Most studies also assessed exercise tolerance by measuring peak oxygen uptake $\left(\mathrm{VO}_{2 \text { peak }}\right)$ during an incremental cycle ergometer test (Cider et al 2003, Cider et al 2012, Mourot et al 2010, Municino et al 2006, Teffaha et al 2011). $\mathrm{VO}_{\text {2peak }}$ is an important prognostic marker in patients with CHF (Myers et al 1998), given that a low $\mathrm{VO}_{2 \text { peak }}$ in $\mathrm{CHF}$ patients is associated with increased mortality (Mancini et al 1991). An increase in $\mathrm{VO}_{2 \text { peak }}$ of $2 \mathrm{~mL} \cdot \mathrm{kg}^{-1}$. $\mathrm{min}^{-1}$ is considered to be clinically relevant in patients with severe CHF (van der Meer et al 2012). The most promising results from the studies included in this review arose from Cider et al (2012), who found significant improvements in $\mathrm{VO}_{2 \text { peak }}\left(2.1 \mathrm{~mL} \cdot \mathrm{kg}^{-1}\right.$. $\mathrm{min}^{-1}$ ) compared to baseline following 8 weeks of water-based therapy. It should be noted, however, that participants in this study had a lower $\mathrm{VO}_{2 \text { peak }}$ at baseline compared to other studies included in this review. This may be due to the participants having combined diagnoses of CHF and type II diabetes mellitus. A combination of CHF and type II diabetes mellitus is associated with a lower $\mathrm{VO}_{2}$ than in patients with only one of these diseases (Guazzi et al 2002). This may mean that the participants in this study had an increased capacity for improvement following hydrotherapy intervention compared to other studies.

Patients with chronic health conditions suffer reductions in HRQOL compared with age-matched norms (Lee et al 2014).
Exercise is a proven modality to significantly improve HRQOL in patients with chronic health conditions and, as such, is an important outcome to assess in any exercise intervention for chronic health conditions (Taylor et al 2014). Interestingly, only half the included studies in this review investigated HRQOL (Cider et al 2003, Cider et al 2012, Municino et al 2006). No significant differences in HRQOL between groups were found (Cider et al 2003, Cider et al 2012) but Cider (2003) and Municino (2006) found significant improvements in total scores from baseline using the disease-specific Minnesota Living with Heart Failure Questionnaire (MLHFQ). Municino et al (2006) recorded a significant reduction in median scores (from 56 to 18) after 3 weeks of water-based exercise. This is a particularly important result given that the MCID for the MLHFQ is a 5-7 point reduction on the overall score (Rector and Cohn 1992). It is important to note that this study also included a hydromassage relaxation therapy component along with a structured and supervised lifestyle change education component to the therapy programme. Education aimed at improving selfmanagement and lifestyle modification has been shown to improve HRQOL in patients with $\mathrm{CHF}$, and is recommended as an essential component in cardiac rehabilitation (Corra et al 2005). Therefore, this added component may have promoted patient reassurance and relaxation, leading to a greater sense of well-being and markedly improved results.

Differences in programme duration and intensity may have been a contributing factor to the variance in results across all studies. It is possible that more significant results may have been elicited if some of the studies had been of a longer duration. It has been suggested that a minimum of 8-12 weeks of exercise training is required to be effective (Piepoli et al 2010); the NZ Heart Foundation (2009) recommends a cardiac rehabilitation programme over 8 weeks for patients with CHF to allow for appropriate physiological adaptations to occur. All studies included in this review which were of three weeks duration or less failed to reach MCID figures for $\mathrm{VO}_{2 \text { peak }}$, with mean results ranging from $1.5-1.8 \mathrm{ml} / \mathrm{kg}$ improvements (Mourot et al 2010, Municino et al 2006, Teffaha et al 2011) and it is possible these studies may have met the MCID for $\mathrm{VO}_{2 \text { peak }}$ if the programmes were longer in duration.

The intensity of exercise interventions may also have affected outcomes across all studies. Many studies utilised a percentage of heart-rate reserve as a measure of intensity. This method may be problematic in patients with CHF as they are commonly on beta-blocker medications (Di Franco et al 2013). The role of beta-blockers is to reduce the effects of sympathetic nervous system activity on the myocardium, thereby reducing heart rate (Di Franco et al 2013). As such, target heart rates may have been difficult for patients to achieve, given that beta-blockers prevent significant increases in heart rate. It has been found that exertion scales such as the Borg Rating of Perceived Exertion correlate well with $\mathrm{VO}_{2 \text { peak }}$ in patients with $\mathrm{CHF}$, even in those using beta-blockers (Levinger et al 2004). Using an exertion scale may therefore be a useful tool to prescribe, monitor intensity and ensure appropriate progression of exercise in patients with CHF.

Based on the evidence found in this review, hydrotherapy appears to be a safe, accessible and well-tolerated form of exercise, with no adverse events reported across any of the included studies. Importantly, adherence was high with only one reported withdrawal across all studies. This completion rate is well above the average for cardiac rehabilitation, with up to $37 \%$ of people failing to complete programmes (Carvalho and Guimaraez 2010). This may prove to be a major benefit of hydrotherapy, as there have been many reported barriers to adhering to land based exercise programmes in patients 
with CHF, including being "painful, "tiresome" and "boring" (Conraads et al 2012). Therefore, if hydrotherapy proves to be as effective as land-based exercise and is better tolerated, it may be a mechanism for overcoming barriers, improving attendance and improving rehabilitation outcomes for people living with $\mathrm{CHF}$.

\section{CONCLUSION}

In the present systematic review, we identified six studies comparing hydrotherapy versus no exercise or land-based exercise training in people with stable chronic heart failure (CHF) of NYHA II-III. There was significant variability in the reporting, components and length of the water-based interventions undertaken by each of the studies. This may account for the variability in exercise tolerance and HRQOL outcomes across all the studies. The quality of available evidence overall was of poor to moderate quality according to the Downs and Black criteria; and therefore further research of higher methodological quality is required before strong recommendations can be made regarding the effect of aquatic-based exercise on exercise tolerance and HRQOL in patients with stable CHF. Such research should include the evaluation of water-based exercise compared with equivalent land-based activities, of appropriate duration and intensity.

\section{KEY POINTS}

- Hydrotherapy appears to be a safe and well tolerated exercise intervention in patients with CHF of NYHA II-III.

- Hydrotherapy appears to improve exercise tolerance and health related quality of life in patients with CHF of NYHA II-III.

- Further high-quality research is required before strong conclusions can be drawn on the effectiveness of hydrotherapy for patients with CHF.

\section{ADDRESS FOR CORRESPONDENCE}

Dr Julie Reeve, Auckland University of Technology, AA 260, Akoranga Campus, Northcote, Private Bag 92006, Auckland. Julie.reeve@aut.ac.nz

\section{REFERENCES}

American Heart Association (2014) Classes of Heart Failure. http://www. heart.org/HEARTORG/Conditions/HeartFailure/AboutHeartFailure/Classesof-Heart-Failure_UCM_306328_Article.jsp [Accessed May 12, 2014]

Becker BE (2009) Aquatic therapy: scientific foundations and clinical rehabilitation applications. Physical Medicine and Rehabilitation 1(9): 859872. DOI: 10.1016/j.pmrj.2009.05.017

Bender T, Karagulle Z, Balint GP, Gutenbrunner C, Balint PV, Sukenik S (2005) Hydrotherapy, balneotherapy, and spa treatment in pain management. Rheumatology International 25(3): 220-224. DOI: 10.1007/s00296-0040487-4

Caminiti G, Volterrani M, Marazzi G, Cerrito A, Massaro R, Sposato B, Arisi A, Rosano G (2009) Hydrotherapy added to endurance training versus endurance training alone in elderly patients with chronic heart failure: a randomized pilot study. International Journal of Cardiology 148(2): 199203. DOI:10.1016/j.ijcard.2009.09.565

Cider A, Schaufelberger M, Stibrant Sunnerhagen K, Andersson B (2003) Hydrotherapy - A new approach to improve function in the older patient with chronic heart failure. The European Journal of Heart Failure 5(4): 527-535.

Cider A, Schaufelberger M, Stibrant Sunnerhagen K, Andersson B (2012) Aquatic exercise is effective in improving exercise performance in patients with heart failure and Type 2 diabetes mellitus. Evidence-Based Complementary and Alternative Medicine 2012: DOI:10.1155/2012/349209

Carvalho VO, Guimaraes GV (2010) An overall view of physical exercise prescription and training monitoring for heart failure patients. Cardiology Journal 17(6): 644-649.

Conraads VM, Deaton C, Piotrowicz E, Santaularia N, Tierney S, Piepoli MF, Pieske B, Schmid J-P, Dickstein K, Ponikowski PP, Jaarsma T (2012)
Adherence of heart failure patients to exercise: barriers and possible solutions: a position statement of the Study Group on Exercise Training in Heart Failure of the Heart Failure Association of the European Society of Cardiology. European Journal of Heart Failure 14(5): 451-458. DOI: 10.1093/eurjhf/hfs048

Corra U, Giannuzzi P, Adamopoulos S, Bjornstad H, Bjarnason-Weherns B, Cohen-Solal A, Dugmore D, Fioretti P, Gaita D, Hambrecht R, Hellermans I, McGee H, Mendes M, Perk J, Saner H, Vanhees L (2005) Executive summary of the Position Paper of the Working Group on Cardiac, Rehabilitation, Exercise, Physiology, \& Working Group on Heart Failure of the European Society of Cardiology: core components of cardiac rehabilitation in chronic heart failure. European Journal of Cardiovascular Prevention \& Rehabilitation 12(4): 321-325. DOI:10.1097/01. hjr.0000173108.76109.88

Di Franco A, Sarullo FM, Salerno Y, Figliozzi S, Parrinello R, Di Pasquale P, Lanza GA (2014) Beta-Blockers and Ivabradine in chronic heart failure: From clinical trials to clinical practice. American Journal of Cardiovascular Drugs 14(2): 101-333. DOI: 10.1007/s40256-013-0057-9

Downs S, Black N (1998) The feasibility of creating a checklist for the assessment of the methodological quality both of randomised and nonrandomised studies of health care interventions. Journal of Epidemiology and Community Health 52(6): 377-384. DOI: 10.1136/jech.52.6.377

Gabrielsen A, Sorensen VB, Pump B, Galatius S, Videbaek R, Bie P, Warberg J, Christensen NJ, Wroblewski H, Kastrup J, Norsk P (2000) Cardiovascular and neuroendocrine responses to water immersion in compensated heart failure. American Journal of Physiology- Heart and Circulatory Physiology 279(4): H1931-1940.

Garin O, Ferrer M, Pont A, Rue M, Kotzeva A, Wiklund I, van Ganse E, Alonso J (2009) Disease-specific health-related quality of life questionnaires for heart failure: a systematic review with meta-analyses. Quality of Life Research 18(1): 71-85. DOI: 10.1007/s11136-008-9416-4

Go AS, Mozaffarian D, Roger VL, Benjamin EJ, Berry JD, Borden WB, Bravata DM, Dai S, Ford ES, Fox CS, Franco S, Fullerton HJ, Gillespie C, Hailpern SM, Heit JA, Howard VJ, Huffman M D, Kissela BM, Kittner SJ, Lackland DT, Lichtman JH, Lisabeth LD, Magid D, Marcus GM, Marelli A, Matchar DB, McGuire DK, Mohler ER, Moy CS, Mussolino ME, Nichol G, Paynter NP, Schreiner PJ, Sorlie PD, Stein J, Turan TN, Virani SS, Wong ND, Woo D, Turner MB; American Heart Association Statistics Committee and Stroke Statistics Subcommittee (2013) Heart disease and stroke statistics--2013 update: a report from the American Heart Association. Circulation 127(1): e6-e245. DOI: 10.1161/CIR.0b013e31828124ad

Guazzi M, Brambilla R, Pontone G, Agostoni P, Guazzi MD (2002) Effect of non-insulin-dependent diabetes mellitus on pulmonary function and exercise tolerance in chronic congestive heart failure. American Journal of Cardiology 89(2): 191-197. DOI: 10.1016/S0002-9149(01)02199-3

Kamioka H, Tsutani K, Okuizumi H, Mutoh Y, Ohta M, Handa S, Okada S, Kitayuguchi J, Kamada M, Shiozawa M, Honda T (2010) Effectiveness of aquatic exercise and balneotherapy: a summary of systematic reviews based on randomized controlled trials of water immersion therapies. Journal of Epidemiology 20(1): 2-12. DOI: 10.2188/jea.JE20090030

Lee KS, Lennie TA, Wu JR, Biddle MJ, Moser DK (2014) Depressive symptoms, health-related quality of life, and cardiac event-free survival in patients with heart failure: a mediation analysis. Quality of Life Research 23(6): 1869-1876. DOI: 10.1007/s11136-014-0636-5

Levinger I, Bronks R, Cody DV, Linton I, Davie A (2004) Perceived exertion as an exercise intensity indicator in chronic heart failure patients on Betablockers. Journal of Sports Science and Medicine 3(YISI 1): 23-27.

Mancini DM, Eisen H, Kussmaul W, Mull R, Edmunds LH Jr, Wilson JR (1991) Value of peak exercise oxygen consumption for optimal timing of cardiac transplantation in ambulatory patients with heart failure. Circulation 83(3): 778-786. DOI: 10.1161/01.CIR.83.3.778

Mant J, Al-Mohammad A, Swain S, Laramee P, Guideline Development, Group (2011) Management of chronic heart failure in adults: synopsis of the National Institute for Health and clinical excellence guideline. Annals of Internal Medicine 155(4): 252-259. DOI: 10.7326/0003-4819-155-4201108160-00009

Moher D, Liberati A, Tetzlaff J, Altman D (2010) Preferred reporting items for systematic reviews and meta-analyses: the PRISMA statement. International Journal of Surgery 8(5): 336-341. DOI: 10.1016/j. ijsu.2010.02.007

Mourot L, Teffaha D, Bouhaddi M, Ounissi F, Vernochet P, Dugue B, Regnard J, Monpère C (2010) Journal of Cardiopulmonary Rehabilitation and Prevention 30(1): 22-27. DOI: 10.1097/HCR.0b013e3181c8595c

Municinó A, Nicolino A, Milanese M, Gronda E, Andreuzzi B, Oliva F, Chiarella, F (2006) Hydrotherapy in advanced heart failure: the Cardio- 
HKT Pilot Study. Monaldi Archives for Chest Disease 66(4): 247-254.

Myers J, Gullestad L, Vagelos R, Do D, Bellin D, Ross H, Fowler MB (1998) Clinical, hemodynamic, and cardiopulmonary exercise test determinants of survival in patients referred for evaluation of heart failure. Annals of Internal Medicine 129(4): 286-293.

NZ Heart Foundation (2009) New Zealand Guideline for the Management of Chronic Heart Failure. http://www.heartfoundation.org.nz/uploads/GuidelineManagement-Chronic-Heart-Failure-5.pdf [Accessed April 21, 2014]

Piepoli MF, Guazzi M, Boriani G, Cicoira M, Corra U, Dalla Libera L, Emdin M, Mele D, Passino C, Vescovo G, Vigorito C, Villani G, Agostini P, Working Group 'Exercise Physiology, Sport Cardiology and Cardiac Rehabilitation' of the Italian Society of Cardiology (2010) Exercise intolerance in chronic heart failure: mechanisms and therapies. Part II. European Journal of Cardiovascular Prevention and Rehabilitation 17(6): 643-648. DOI: 10.1097/HJR.0b013e32833f3aa5

Rector TS, Cohn JN (1992) Assessment of patient outcome with the Minnesota Living with Heart Failure questionnaire: reliability and validity during a randomized, double-blind, placebo-controlled tria of pimobendan. American Heart Journal 124(4): 1017-1025. DOI: 10.1016/0002-8703(92)90986-6

Selig SE, Levinger I, Williams AD, Smart N, Holland DJ, Maiorana A, Green DJ, Hare DL (2010) Exercise \& Sports Science Australia Position Statement on exercise training and chronic heart failure. Journal of Science and Medicine in Sport 13(3): 288-294. DOI:10.1016/j.jsams.2010.01.004

Shoemaker MJ, Curtis AB, Vangsnes E, Dickinson MG (2012) Triangulating clinically meaningful change in the six-minute walk test in individuals with chronic heart failure: a systematic review. Cardiopulmonary Physical Therapy Journal 23(3): 5-15.

Somaratne JB, Berry C, McMurray JJ, Poppe KK, Doughty RN, Whalley GA (2009) The prognostic significance of heart failure with preserved left ventricular ejection fraction: a literature-based meta-analysis. European Journal of Heart Failure 11(9): 855-862. DOI: 10.1093/eurjhf/hfp103
Svealv BG, Cider A, Tang MS, Angwald E, Kardassis D, Andersson B (2009) Benefit of warm water immersion on biventricular function in patients with chronic heart failure. Cardiovascular ultrasound 7(1). DOI: 10.1186/14767120-7-33

Taylor RS, Sagar VA, Davies EJ, Briscoe S, Coats AJS, Dalal H, Lough F, Rees K, Singh S (2014) Exercise-based rehabilitation for heart failure (Review). Cochrane database of systematic reviews 4. DOI: 10.1002/14651858. CD003331.pub4.

Teffaha D, Mourot L, Vernochet P, Ounissi F, Regnard J, Monpere C, Dugu $B$ (2011) Relevance of water gymnastics in rehabilitation programs in patients with chronic heart failure or coronary artery disease with normal left ventricular function. Journal of Cardiac Failure 17(8): 676-683. DOI:10.1016/j.cardfail.2011.04.008

van der Meer S, Zwerink M, van Brussel M, van der Valk P, Wajon E, van der Palen J (2012) Effect of outpatient exercise training programmes in patients with chronic heart failure: a systematic review. European Journal of Preventative Cardiology 19(4): 795-803. DOI: 10.1177/1741826711410516

Wong CY, Chaudhry SI, Desai MM, Krumholz HM (2011) Trends in comorbidity, disability, and polypharmacy in heart failure. American Journal of Medicine 124(2): 136-143. DOI: 10.1016/j.amjmed.2010.08.017

Working Group on Cardiac, Rehabilitation, Exercise, Physiology, \& Working Group on Heart Failure of the European Society of Cardiology (2001) Recommendations for exercise training in chronic heart failure patients. European Heart Journal 22(2): 125-135. DOI: 10.1053/euhj.2000.2440

Yancy CW, Jessup M, Bozkurt B, Butler J, Casey DE, Drazner MH, Fonarow GC, Geraci SA, Horwich T, Januzzi JL, Johnson MR, Kasper EK, Levy WC, Masoudi FA, McBride PE, McMurray JJV, Mitchell JE, Peterson PE, Riegel B, Flora S, Stevenson LW, Tang WH, Tsai EJ, Wilkoff BL (2013) 2013 ACCF/ AHA Guideline for the Management of Heart Failure. Journal of the American College of Cardiology 62(16): e147-e239. DOI: http://dx.doi. org/10.1016/j.jacc.2013.05.019

\section{APPENDIX A: Key words used in search databases}

\begin{tabular}{|c|c|c|}
\hline \multicolumn{3}{|l|}{ Key words "OR" } \\
\hline Hydrotherap* & "immersion-therap*" & "water-based" \\
\hline "Aquatic exercise" & Balenotherap* & "water gymnastic*" \\
\hline "aqua therap*" & "pool therap*" & Aquatic* \\
\hline \multicolumn{3}{|l|}{ Key words "AND" } \\
\hline "Heart failure" & "chronic heart" & "congestive heart" \\
\hline $\begin{array}{l}\text { "ventricular dysfunction" } \\
\text { "heart disease" }\end{array}$ & $\mathrm{CHF}$ & "heart dysfunction" \\
\hline
\end{tabular}

Note: *Truncation symbol

\section{APPENDIX B: Selection criteria for studies to be included in critique}

\section{Study Selection Criteria}

In English language

Randomised controlled trials and quasi-experimental studies

Outcome measures: any exercise-related and HRQOL outcome measures

Publication dates between year 1995-2014

Subjects: Humans, >18-years-old, diagnosed with CHF

Intervention: Hydrotherapy

\section{Study Exclusion Criteria}

Systematic and/or literature reviews

Immersion only (no exercise/movement in water) 
